\title{
High expression of class III $\beta$-tubulin in upper gastrointestinal cancer types
}

\author{
DORIS HÖFLMAYER ${ }^{1 *}$, ERAY ÖZTÜRK ${ }^{1 *}$, CORNELIA SCHROEDER ${ }^{2}$, \\ CLAUDIA HUBE-MAGG ${ }^{1}$, NICLAS C. BLESSIN ${ }^{1}$, RONALD SIMON ${ }^{1,2}$, DAGMAR S. LANG ${ }^{1}$, \\ EMILY NEUBAUER ${ }^{1}$, COSIMA GÖBEL ${ }^{1}$, MARIE-CHRISTINE HEINRICH ${ }^{1}$, CHRISTOPH FRAUNE $^{1}$, \\ KATHARINA MÖLLER ${ }^{1}$, MORITZ ARMBRUST ${ }^{1}$, MORTON FREYTAG ${ }^{1}$, ANDREA HINSCH $^{1}$, CLARA LÜHR ${ }^{1}$, \\ MAGDALENA NOACK ${ }^{1}$, VIKTOR REISWICH ${ }^{1}$, SÖREN WEIDEMANN ${ }^{1}$, MAXIMILIAN BOCKHORN ${ }^{2}$, \\ DANIEL PEREZ $^{2}$, JAKOB R. IZBICKI ${ }^{2}$, GUIDO SAUTER ${ }^{1}$ and FRANK JACOBSEN ${ }^{1}$ \\ ${ }^{1}$ Institute of Pathology; ${ }^{2}$ General, Visceral and Thoracic Surgery Department and Clinic, \\ University Medical Center Hamburg-Eppendorf, D-20246 Hamburg, Germany
}

Received January 4, 2018; Accepted September 10, 2018

DOI: $10.3892 / 01.2018 .9502$

\begin{abstract}
Class III $\beta$-tubulin (TUBB3) is a component of microtubules of neuronal cells that is upregulated in various cancer entities. To better understand the role of TUBB3 in upper gastrointestinal tract cancer types, the present study assessed TUBB3 expression in tissue microarrays including 189 gastric and 428 esophageal cancer. TUBB3 expression was detected in $62.4 \%$ of gastric cancer, $73.8 \%$ of esophageal adenocarcinoma and $88.7 \%$ of esophageal squamous cell cancer, while control samples of normal esophageal and gastric epithelium were TUBB3-negative. TUBB3 positivity was not associated with the International Union Against Cancer classification, World Health Organization grading, lymph node involvement or distant metastasis in any entity. Of note, TUBB3 expression was associated with tumor localization and prognosis in gastric cancer, with the tumor stage in esophageal adenocarcinoma, and with the resection margin in esophageal squamous cell cancer. In conclusion, the substantial rate of positivity for TUBB3 already in early stages of gastric cancer in combination with the lack of a further increase in frequency with tumor stage, may suggest, that TUBB3 upregulation is rather relevant for cancer development than for cancer progression. TUBB3
\end{abstract}

Correspondence to: Dr Ronald Simon, Institute of Pathology, University Medical Center Hamburg-Eppendorf, 52 Martinistrasse, D-20246 Hamburg, Germany

E-mail: r.simon@uke.de

${ }^{*}$ Contributed equally

Abbreviations: TUBB3, Class III $\beta$ tubulin; TMA, tissue microarray; UICC, International Union Against Cancer

Key words: tubulin, gastric and esophageal cancer, TMA might be a suitable prognostic biomarker in gastric cancer types.

\section{Introduction}

Upper gastrointestinal cancers are among the leading causes of cancer-associated mortality worldwide. Approximately 1.5 million people are diagnosed with gastric and esophageal cancer each year $(1,2)$. Despite improvements in diagnosis and therapy in the last decades, the outcome for patient with gastric and esophageal cancers remains poor with 5-year survival rates not exceeding 20-30\% in Western societies (3-5). The molecular mechanisms underlying carcinogenesis remain largely elusive. Accordingly, molecular markers allowing for prediction of the clinical course of these diseases are currently lacking. Hence, there is a high demand for molecular markers to predict tumor aggressiveness and response to therapy for these cancer types.

Microtubules are multifunctional cytoskeletal proteins involved in numerous cellular processes including maintenance of cell shape, intracellular transport and chromosome segregation during mitosis and meiosis. Microtubules are composed of polymers of $\alpha$ - and $\beta$-tubulin heterodimers. Class III $\beta$-tubulin (TUBB3) is typically expressed in cells of neuronal origin, where it contributes to the formation of dynamic microtubules essential for neurite formation and maintenance (6). Several lines of evidence suggest that TUBB3 also has an important role in tumor development. In fact, overexpression of TUBB3 has been linked to poor clinical outcome in numerous epithelium-derived tumor types, including non-small cell lung (7), bladder (8), breast (9), ovarian (10) and prostate cancer (11). Several studies analyzing gastric and/or esophageal cancer specimens $(n=29-149)$ have also suggested clinically relevant roles of TUBB3 expression levels in upper gastrointestinal cancer (12-14). Of note, elevated levels of TUBB3 expression have been associated with a reduced response to taxane-based microtubule-targeting cancer therapy $(7,10-12,15)$. 
Here we tested retrospectively TUBB3 expression in upper gastrointestinal cancers from 230 gastric and 594 esophageal cancers on tissue microarrays (TMA) and report the clinical follow up from 189 gastric and 428 esophageal cancers.

\section{Patients and methods}

Patients. The 230 patients [mean age $( \pm \mathrm{SD}), 67$ years $( \pm 12)$; female/male-ratio, 0.51$]$ with gastric and 594 patients [mean age $( \pm \mathrm{SD}), 62$ years $( \pm 10)$; female/male-ratio, 0.25$]$ with esophageal cancer received surgical treatment at the Department of General, Visceral and Thoracic Surgery, University Medical Center Hamburg-Eppendorf (Hamburg, Germany) between June 1994 and October 2006, and between January 1992 and December 2014, respectively. TUBB3 staining and follow-up data was available for 93 patients with gastric cancer with a median time of 13 months and for 393 esophageal cancer patients with a median time of 41 months. Tumors were staged according to the sixth edition of the tumor-nodes-metastasis classification, graded and histologically subtyped according to the recommendations of the International Union Against Cancer (UICC) (16). Data on neoadjuvant or adjuvant cytotoxic therapy regimens or response to treatment were unavailable. The TMA manufacturing was performed as described in previous studies $(17,18)$. Each TMA block contained internal controls of normal esophageal and gastric tissue taken from the same patient cohort.

The Ethics Committee of the Ärztekammer Hamburg approved the present study (no. WF-049/09). According to local laws (HmbKHG §12a), informed consent was not required. Patient records/information were anonymized prior to analysis. All work was performed in compliance with the Helsinki Declaration.

Immunohistochemistry. TUBB3 staining and scoring was performed as described in a previous study (9). The recombinant rabbit monoclonal anti-TUBB3 antibody clone EPR1568Y was used at a dilution 1:150 of (cat. no. ab68193; Abcam, Cambridge, UK). Staining was observed in the cytoplasm of TUBB3-expressing cells and scored as 'negative' ( 0$)$, 'weak' ( $1+$ in $\leq 70 \%$ of tumor cells or $2+$ in $\leq 30 \%$ of tumor cells), 'moderate' ( $1+$ in $>70 \%$ of tumor cells, or $2+$ in $31-70 \%$ of tumor cells, or $3+$ in $\leq 30 \%$ of tumor cells) or 'strong' $(2+$ in $>70 \%$ of tumor cells or $3+$ in $>30 \%$ of tumor cells) (Figs. 1 and 2).

Statistical analysis. JMP 12.0 software (SAS Institute Inc., Carey, NC, USA) was used to calculate contingency tables and P-values with the chi-squared (likelihood) test. Kaplan-Meier curves were drawn and significant differences between groups were assessed by the log-rank method. Cox regression analysis was used to compare hazard ratios in univariate and multivariate models. $\mathrm{P} \leq 0.05$ was considered to indicate a statistically significant difference.

\section{Results}

TUBB3-staining. The results of the TMA analysis were interpretable for a total of 189/230 (82\%) of gastric and 431/594 (73\%)
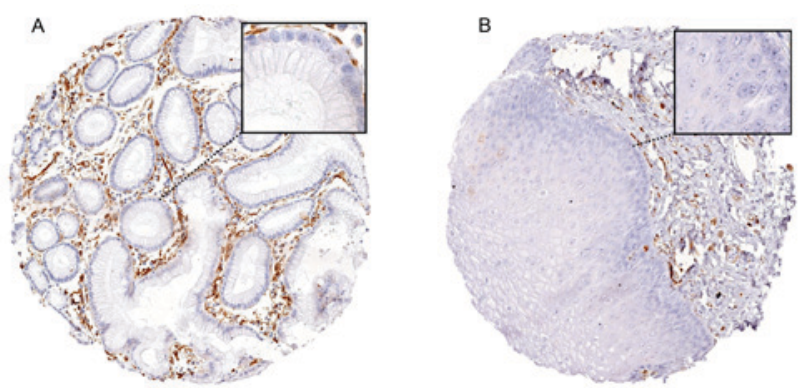

Figure 1. Representative images of $600 \mu$ m-tissue spots at magnification, $\mathrm{x} 100$ and $\mathrm{x} 400$, respectively, showing normal (A) gastric and (B) esophageal tissue. Note that glandular cells in the gastric and squamous epithelial cells in the esophageal tissue are not stained, while stromal cells are positive in both tissues.
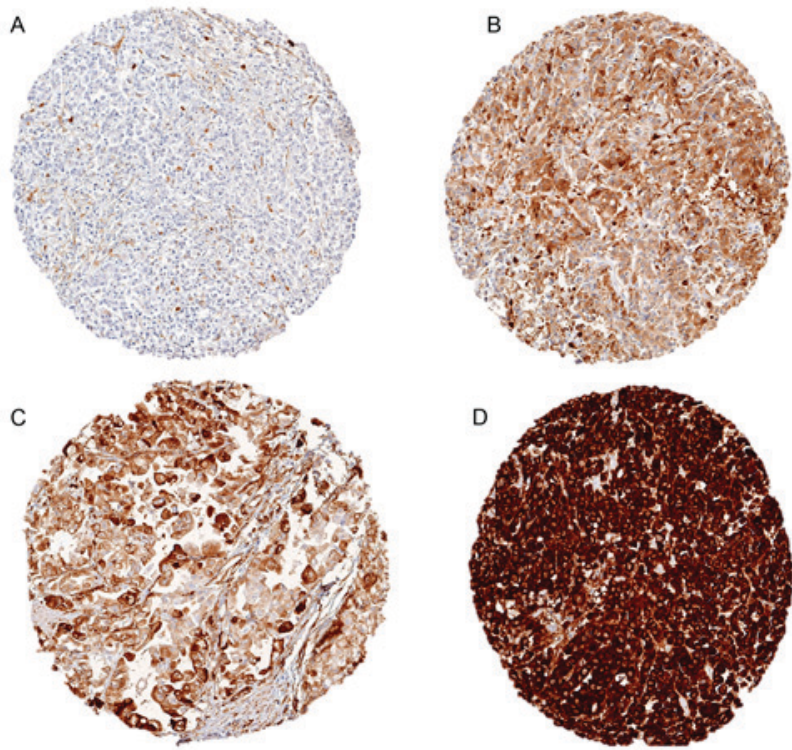

Figure 2. Representative images of $600 \mu \mathrm{m}$-tissue spots showing (A) negative, (B) weak, (C) moderate and (D) strong class III $\beta$-tubulin expression in gastric cancer (magnification, x100).
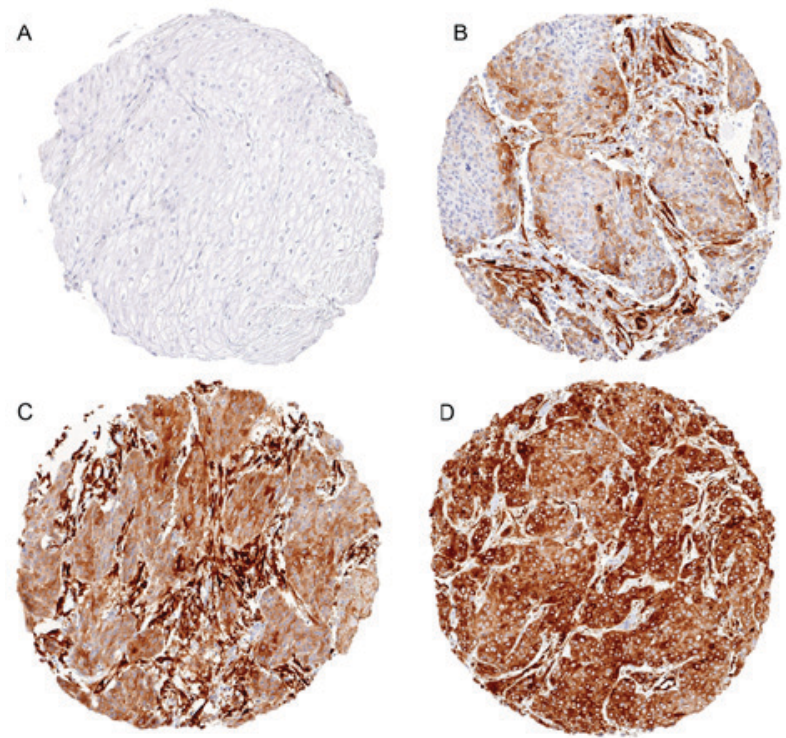

Figure 3. Representative images of $600 \mu \mathrm{m}$-tissue spots showing (A) negative, (B) weak, (C) moderate and (D) strong class III $\beta$-tubulin expression in esophageal squamous cell cancer (magnification, x100). 
Table I. Association between TUBB3 expression and gastric cancer phenotype.

\begin{tabular}{|c|c|c|c|c|c|c|}
\hline \multirow[b]{2}{*}{ Parameter } & \multirow[b]{2}{*}{ No. evaluable } & \multicolumn{4}{|c|}{ TUBB3 (\%) } & \multirow[b]{2}{*}{ P-value } \\
\hline & & Negative & Weak & Moderate & Strong & \\
\hline All cancers & 189 & 37.6 & 11.1 & 18.0 & 33.3 & \\
\hline \multicolumn{7}{|l|}{ Tumor stage ${ }^{a}$} \\
\hline pT1+2 & 125 & 36.8 & 12.0 & 19.2 & 32.0 & \multirow[t]{2}{*}{0.7753} \\
\hline pT3+4 & 62 & 37.1 & 9.7 & 16.1 & 37.1 & \\
\hline \multicolumn{7}{|l|}{ UICC-classification } \\
\hline I & 31 & 32.3 & 9.7 & 22.6 & 35.5 & \multirow[t]{4}{*}{0.8227} \\
\hline II & 28 & 35.7 & 21.4 & 14.3 & 28.6 & \\
\hline III & 86 & 41.9 & 8.1 & 18.6 & 31.4 & \\
\hline IV & 44 & 34.1 & 11.4 & 15.9 & 38.6 & \\
\hline \multicolumn{7}{|l|}{ Laurén classification ${ }^{\mathrm{a}}$} \\
\hline Diffuse & 61 & 52.5 & 13.1 & 14.8 & 19.7 & \multirow[t]{3}{*}{0.0484} \\
\hline Mixed & 14 & 42.9 & 7.1 & 21.4 & 28.6 & \\
\hline Intestinal & 109 & 28.4 & 11.0 & 20.2 & 40.4 & \\
\hline \multicolumn{7}{|l|}{ WHO grading ${ }^{\mathrm{a}}$} \\
\hline G1 & 2 & 50.0 & 0.0 & 0.0 & 50.0 & \multirow[t]{3}{*}{0.2345} \\
\hline $\mathrm{G} 2$ & 58 & 25.9 & 8.6 & 22.4 & 43.1 & \\
\hline G3 & 126 & 42.1 & 12.7 & 15.9 & 29.4 & \\
\hline \multicolumn{7}{|l|}{ Tumor localization $^{\mathrm{a}}$} \\
\hline Antrum & 13 & 23.1 & 38.5 & 30.8 & 7.7 & \multirow[t]{4}{*}{$0.0012^{\mathrm{b}}$} \\
\hline Corpus & 7 & 42.9 & 0.0 & 28.6 & 28.6 & \\
\hline Cardia & 47 & 17.0 & 19.1 & 12.8 & 51.1 & \\
\hline Other/not further specified & 93 & 46.2 & 7.5 & 14.0 & 32.3 & \\
\hline \multicolumn{7}{|l|}{ Lymph node metastasis ${ }^{\mathrm{a}}$} \\
\hline No & 53 & 34.0 & 17.0 & 18.9 & 30.2 & \multirow[t]{2}{*}{0.4896} \\
\hline N1 & 133 & 37.6 & 9.0 & 18.0 & 35.3 & \\
\hline \multicolumn{7}{|l|}{ Distant metastasis ${ }^{\mathrm{a}}$} \\
\hline M0 & 129 & 38.8 & 10.9 & 16.3 & 34.1 & \multirow[t]{2}{*}{0.4076} \\
\hline M1 & 22 & 22.7 & 13.6 & 13.6 & 50.0 & \\
\hline
\end{tabular}

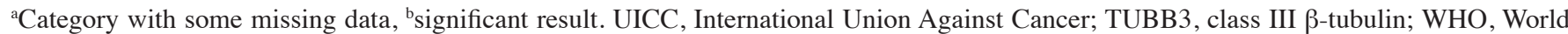
Health Organization.

of esophageal tumor samples. In the non-informative TMA spots (18\% for gastric cancer and $27 \%$ for esophageal cancer), the tissue sample was lacking or no unequivocal cancer tissue was observed. Normal gastric and esophageal tissues exhibited no staining under the selected experimental conditions. Fig. 1 shows representative images of normal gastric and esophageal tissue.

TUBB3-expression in gastric cancer. In gastric cancer, positive staining for TUBB3 was detected in 118 of 189 analyzable spots $(62.4 \%)$ and was rated weak in $11.1 \%$, moderate in $18 \%$ and strong in $33.3 \%$ of these samples. Representative images of TUBB3 staining in gastric cancers are given in Fig. 2. TUBB3 expression was unrelated to tumor stage, UICC stage, Lauren classification, WHO grading, and presence of lymph node or distant metastasis ( $P>0.05$ each; Table I). TUBB3 expression varied from 53.8 to $83.0 \%$ with the tumor localization $(\mathrm{P}=0.0012$; Table I).

TUBB3-expression in esophageal cancer. In esophageal cancer, cytoplasmic TUBB3 staining was detected in 345 of 428 analyzable tumors (80.7\%), including 233 adenocarcinomas and 195 squamous cell cancers. TUBB3 staining in adenocarcinomas (squamous cell cancers) was considered weak in $18.0 \%$ (11.8\%), moderate in $19.7 \%$ (19.0\%) and strong in $36.1 \%$ (57.9\%) of these samples. Representative images of TUBB3 staining in esophageal cancers are given in Fig. 3. In esophageal adenocarcinomas, no association between TUBB3 and UICC stage, WHO grading, or the presence of lymph node or distant metastasis was identified ( $P>0.05$ each; Table II). Only the tumor stage was significantly associated with TUBB3 expression ( $\mathrm{P}=0.0289$; Table II). In esophageal squamous cell carcinomas, only the resection margin 
Table II. Association between TUBB3 expression and esophageal adenocarcinoma phenotype.

\begin{tabular}{|c|c|c|c|c|c|c|}
\hline \multirow[b]{2}{*}{ Parameter } & \multirow[b]{2}{*}{ No. evaluable } & \multicolumn{4}{|c|}{ TUBB3 (\%) } & \multirow[b]{2}{*}{ P-value } \\
\hline & & Negative & Weak & Moderate & Strong & \\
\hline All cancers & 233 & 26.2 & 18.0 & 19.7 & 36.1 & \\
\hline \multicolumn{7}{|c|}{ Tumor stage $\mathrm{a}^{\mathrm{a}}$} \\
\hline pT1a-b & 44 & 29.5 & 29.5 & 27.3 & 13.6 & \multirow[t]{4}{*}{$0.0289^{b}$} \\
\hline pT2 & 25 & 32.0 & 16.0 & 24.0 & 28.0 & \\
\hline pT3 & 143 & 23.1 & 15.4 & 18.9 & 42.7 & \\
\hline pT4a-b & 17 & 35.3 & 17.6 & 5.9 & 41.2 & \\
\hline \multicolumn{7}{|c|}{ UICC-classification ${ }^{\mathrm{a}}$} \\
\hline I & 43 & 32.6 & 23.3 & 25.6 & 18.6 & \multirow[t]{4}{*}{0.0534} \\
\hline II & 26 & 19.2 & 11.5 & 38.5 & 30.8 & \\
\hline III & 134 & 23.9 & 19.4 & 15.7 & 41.0 & \\
\hline IV & 25 & 36.0 & 8.0 & 16.0 & 40.0 & \\
\hline \multicolumn{7}{|c|}{ WHO grading ${ }^{\mathrm{a}}$} \\
\hline G1 & 9 & 22.2 & 22.2 & 22.2 & 33.3 & \multirow[t]{4}{*}{0.8693} \\
\hline $\mathrm{G} 2$ & 85 & 24.7 & 20.0 & 21.2 & 34.1 & \\
\hline G3 & 130 & 26.9 & 16.2 & 20.0 & 36.9 & \\
\hline G4 & 5 & 40.0 & 40.0 & 0.0 & 20.0 & \\
\hline \multicolumn{7}{|c|}{ Resection margin ${ }^{\mathrm{a}}$} \\
\hline 0 & 162 & 26.5 & 18.5 & 23.5 & 31.5 & \multirow[t]{3}{*}{0.0961} \\
\hline 1 & 63 & 27.0 & 17.5 & 12.7 & 42.9 & \\
\hline 2 & 3 & 0.0 & 0.0 & 0.0 & 100.0 & \\
\hline \multicolumn{7}{|c|}{ Lymph node metastasis ${ }^{\mathrm{a}}$} \\
\hline pNO & 61 & 29.5 & 18.0 & 26.2 & 26.2 & \multirow[t]{4}{*}{0.4443} \\
\hline $\mathrm{pN} 1$ & 42 & 16.7 & 23.8 & 23.8 & 35.7 & \\
\hline $\mathrm{pN} 2$ & 57 & 28.1 & 15.8 & 15.8 & 40.4 & \\
\hline $\mathrm{pN} 3$ & 64 & 29.7 & 15.6 & 14.1 & 40.6 & \\
\hline \multicolumn{7}{|c|}{ Distant metastasis $^{\mathrm{a}}$} \\
\hline 0 & 2 & 0.0 & 50.0 & 0.0 & 50.0 & \multirow[t]{2}{*}{0.2737} \\
\hline 1 & 26 & 38.5 & 7.7 & 15.4 & 38.5 & \\
\hline
\end{tabular}

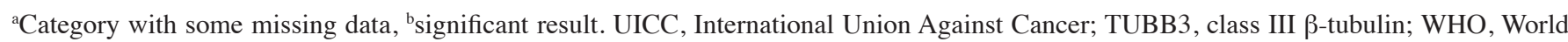
Health Organization.

was significantly associated with TUBB3 (P<0.05; Table III). For the association of TUBB3 with the tumor stage a similar trend as in the adenocarcinomas was observed.

Kaplan-meier analysis. Follow-up data were available from 93 patients with gastric cancer and 393 patients with esophageal cancer (204 adenocarcinomas and 189 squamous cell cancers) with interpretable TUBB3 staining on the TMA. While in gastric cancer TUBB3 expression was associated with shorter overall survival (Fig. 4A and B), TUBB3 expression had no impact on the survival of esophageal cancer patients $(\mathrm{P}>0.05$; Fig. 4C and D).

Multivariate analysis. Hazard ratios for overall survival were calculated. In gastric cancer, TUBB3 expression was an independent risk factor for shorter survival ( $\mathrm{P}<0.05$; Table IV).

\section{Discussion}

The results of the present study demonstrate that TUBB3 is frequently expressed in upper gastrointestinal cancer types associated with patient prognosis only in gastric cancer, but not in esophageal adenocarcinoma and esophageal squamous cell cancer.

TUBB3 expression was identified in $62.4 \%$ of the 189 gastric cancer tissues, in $73.8 \%$ of the 233 esophageal adenocarcinoma tissues and $88.7 \%$ of the 195 esophageal squamous cell cancer tissues in the present study, but was undetectable in the respective normal tissue samples. In principle, these immunohistochemical results are compatible with earlier studies on these tumor types. This particularly applies to gastric tumors, where two earlier studies on gastric cancer tissues ( $n=115$ and 146) reported comparable data, 
Table III. Association between TUBB3 expression and esophageal squamous cell cancer phenotype.

\begin{tabular}{|c|c|c|c|c|c|c|}
\hline \multirow[b]{2}{*}{ Parameter } & \multirow[b]{2}{*}{ No. evaluable } & \multicolumn{4}{|c|}{ TUBB3 (\%) } & \multirow[b]{2}{*}{ P-value } \\
\hline & & Negative & Weak & Moderate & Strong & \\
\hline All cancers & 195 & 11.3 & 11.8 & 19.0 & 57.9 & \\
\hline \multicolumn{7}{|l|}{ Tumor stage } \\
\hline pT1a-b & 31 & 19.4 & 12.9 & 32.3 & 35.5 & 0.1715 \\
\hline pT2 & 43 & 11.6 & 16.3 & 16.3 & 55.8 & \\
\hline pT3 & 109 & 9.2 & 11.0 & 16.5 & 63.3 & \\
\hline pT4a-b & 12 & 8.3 & 0.0 & 16.7 & 75.0 & \\
\hline \multicolumn{7}{|c|}{ UICC-classification $^{\mathrm{a}}$} \\
\hline I & 46 & 13.0 & 8.7 & 26.1 & 52.2 & 0.5155 \\
\hline II & 47 & 6.4 & 17.0 & 17.0 & 59.6 & \\
\hline III & 62 & 12.9 & 6.5 & 19.4 & 61.3 & \\
\hline IV & 39 & 10.3 & 17.9 & 12.8 & 59.0 & \\
\hline \multicolumn{7}{|c|}{ WHO grading } \\
\hline G1 & 3 & 33.3 & 0.0 & 0.0 & 66.7 & 0.7412 \\
\hline G2 & 124 & 10.5 & 11.3 & 21.0 & 57.3 & \\
\hline G3 & 68 & 11.8 & 13.2 & 16.2 & 58.8 & \\
\hline \multicolumn{7}{|c|}{ Resection margin ${ }^{\mathrm{a}}$} \\
\hline 0 & 148 & 14.2 & 11.5 & 18.2 & 56.1 & $0.0461^{\mathrm{b}}$ \\
\hline 1 & 38 & 0.0 & 13.2 & 23.7 & 63.2 & \\
\hline 2 & 8 & 12.5 & 0.0 & 12.5 & 75.0 & \\
\hline \multicolumn{7}{|c|}{ Lymph node metastasis ${ }^{\mathrm{a}}$} \\
\hline $\mathrm{pN} 0$ & 91 & 11.0 & 9.9 & 18.7 & 60.4 & 0.9046 \\
\hline pN1 & 41 & 9.8 & 14.6 & 17.1 & 58.5 & \\
\hline $\mathrm{pN} 2$ & 37 & 8.1 & 16.2 & 24.3 & 51.4 & \\
\hline $\mathrm{pN} 3$ & 21 & 14.3 & 9.5 & 9.5 & 66.7 & \\
\hline \multicolumn{7}{|c|}{ Distant metastasis $^{\mathrm{a}}$} \\
\hline 0 & 1 & 100.0 & 0.0 & 0.0 & 0.0 & 0.1828 \\
\hline 1 & 39 & 7.7 & 17.9 & 12.8 & 61.5 & \\
\hline 1 & 26 & 38.5 & 7.7 & 15.4 & 38.5 & \\
\hline
\end{tabular}

${ }^{\mathrm{a} C}$ Category with some missing data, ${ }^{\mathrm{b}}$ significant result. UICC, International Union Against Cancer; TUBB3, class III $\beta$-tubulin; WHO, World Health Organization.

Table IV. Hazard ratio for overall survival of established prognostic parameter and TUBB3 expression in gastric cancer types.

\begin{tabular}{lcc}
\hline Variable & Univariate analysis & Multivariate analysis \\
\hline $\begin{array}{l}\text { Tumor stage } \\
\text { pT3+4 vs. pT1+2 }\end{array}$ & $2.67(1.66-4.30)^{\mathrm{c}}$ & $1.67(1.00-2.77)$ \\
WHO grading & $1.65(1.00-2.83)^{\mathrm{a}}$ & $2.22(1.29-3.95)^{\mathrm{a}}$ \\
G3 vs. G1+2 & & \\
Lymph node metastasis & $4.43(2.25-10.1)^{\mathrm{c}}$ & $3.11(1.54-7.20)^{\mathrm{b}}$ \\
Positive vs. negative & & \\
TUBB3 expression & $2.23(1.28-4.08)^{\mathrm{a}}$ & $2.18(1.22-4.12)^{\mathrm{a}}$ \\
Positive vs. negative &
\end{tabular}

${ }^{\mathrm{a}} \mathrm{P} \leq 0.05,{ }^{\mathrm{b}} \mathrm{P} \leq 0.001,{ }^{\mathrm{c}} \mathrm{P} \leq 0.0001$. Confidence interval (95\%) in brackets. TUBB3, class III $\beta$-tubulin; WHO, World Health Organization. 
A

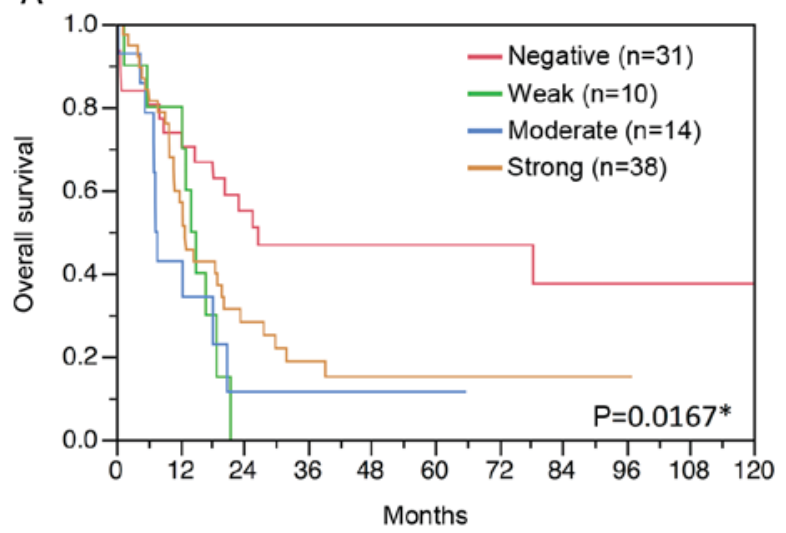

C

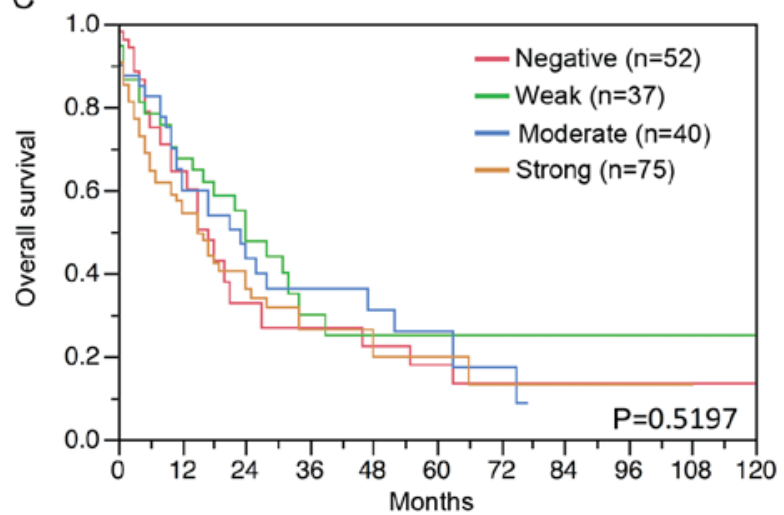

B

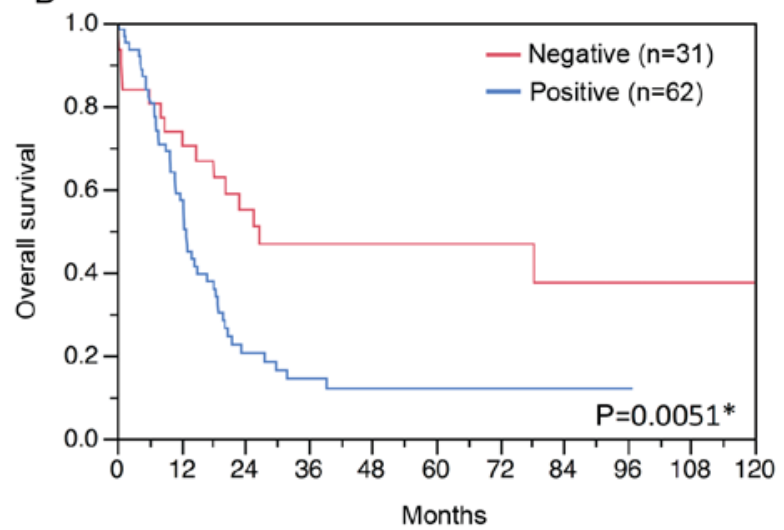

$\mathrm{D}$

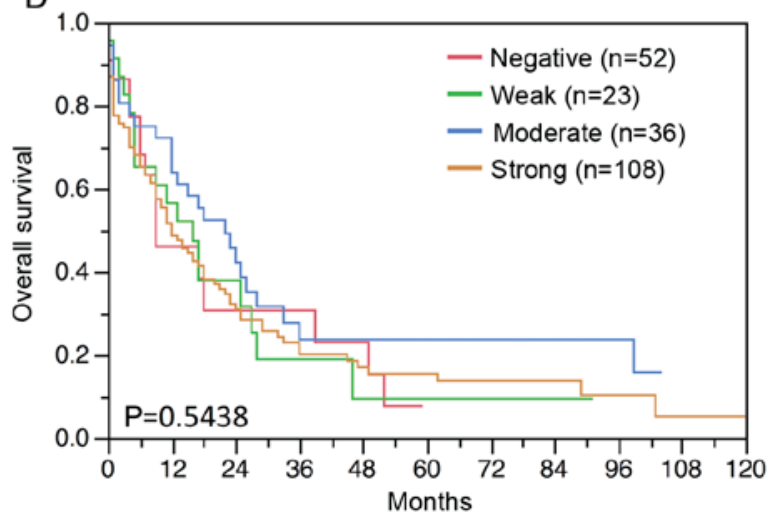

Figure 4. Kaplan-Meier analysis of overall survival and (A) negative, weak, moderate, or strong TUBB3 expression in gastric cancer, (B) negative vs. positive (weak, moderate, or strong) TUBB3 expression in gastric cancer, (C) in esophageal adenocarcinoma, and in (D) esophageal squamous cell cancer. *Significant overall P-value. TUBB3, class III $\beta$-tubulin.

namely detectable TUBB3 expression in 36 and $53 \%$ of tumor samples $(12,19)$. The results of two earlier studies on esophageal squamous cell cancers were more conflicting, reporting TUBB3-positive rates of 7 and 95\%, respectively $(14,20)$. The striking discrepancy of these data is typical for studies using 'homemade' immunohistochemical protocols. It is known, that the use of different antibodies, immunohistochemistry protocols and scoring criteria can result in discrepant data (21).

The important function of TUBB3 in the maintenance of the dynamic plasticity of microtubules $(22,23)$-a prerequisite for cell motility, invasive growth, mitotic spindle orientation, and cell cycle progression-would be consistent with a significant role for TUBB3 in tumor development and progression. The high frequency of detectable TUBB3 staining in early gastric cancer in combination with the lack of a further elevation in frequency with the tumor stage increasing, may suggest that up regulation of TUBB3 is an event in carcinogenesis of gastric cancer and has a relevance in cancer development rather than cancer progression. Other studies have failed to identify an association between TUBB3 expression and clinico-pathological parameters or patient prognosis in gastric or esophageal carcinomas $(12,19,20)$. In the present study, analysis of a much larger number of tumors did reveal a significant association with patient outcome in gastric cancer providing some arguments for TUBB3 testing. This is in line to the results on the predictive value of TUBB3 in a variety of other cancer types. Using the same staining protocol, another recent study by our group identified the prognostic value of TUBB3 in prostate cancer, which was independent of established pre- and post-operatively available prognostic features (24). Others studies have reported TUBB3 overexpression is linked to late tumor stage and poor prognosis in breast (25), lung $(26,27)$, colon $(28)$, ovarian $(10,29,30)$, prostate $(11,24)$ and several neurological cancers $(28)$.

The present study was a retrospective study. Thus it remains to be seen whether the prognostic value of TUBB3 expression in gastric cancer can be validated in a prospective study.

In summary, the results of the present study demonstrate that TUBB3 is frequently expressed in upper gastrointestinal cancer types, including esophageal and gastric tumors. For gastric cancer, TUBB3 expression might be a prognostic factor.

\section{Acknowledgements}

The authors would like to thank Mrs. Janett Lütgens, Mrs. Sünje Seekamp and Mrs. Inge Brandt (Institute of Pathology, University Medical Center Hamburg-Eppendorf) for excellent technical assistance.

\section{Funding}

No funding was received.

\section{Availability of data and materials}

All data generated or analyzed during this study are included in this published article. 


\section{Authors' contributions}

DH, FJ, RS and GS designed the study and drafted the manuscript. EÖ, CS and JRI participated in study design. EN, $\mathrm{CG}, \mathrm{MCH}, \mathrm{CF}, \mathrm{KM}, \mathrm{MA}, \mathrm{MF}$ and $\mathrm{AH}$ performed immunohistochemical analysis and scoring. CL, VR, SW and MN participated in pathology data analysis. $\mathrm{CH}-\mathrm{M}, \mathrm{NCB}$ and RS performed statistical analysis. MB, DP, and DSL participated in data interpretation and helped to draft the manuscript. All authors read and approved the final manuscript.

\section{Ethics approval and consent to participate}

The Ethics Committee of the Ärztekammer Hamburg approved the study protocol (WF-049/09). According to local laws (HmbKHG \$12a), patient informed consent was not required. Patient records/information were anonymized and de-identified prior to analysis. All procedures have been performed in compliance with the principles outlined in the Helsinki Declaration.

\section{Patient consent for publication}

Not applicable.

\section{Competing interests}

The authors declare that they have no competing interests.

\section{References}

1. Zhang Y: Epidemiology of esophageal cancer. World J Gastroenterol 19: 5598-5606, 2013.

2. Pasechnikov V, Chukov S, Fedorov E, Kikuste I and Leja M: Gastric cancer: Prevention, screening and early diagnosis. World J Gastroenterol 20: 13842-13862, 2014.

3. Cancer Genome Atlas Research Network; AnalysisWorking Group: Asan University; BC Cancer Agency; Brigham and Women's Hospital; Broad Institute; Brown University; Case Western Reserve University; Dana-Farber Cancer Institute; Duke University, et al: Integrated genomic characterization of oesophageal carcinoma. Nature 541: 169-175, 2017.

4. Moro K, Nagahashi M, Naito T, Nagai Y, Katada T, Minagawa M, Hasegawa J, Tani T, Shimakage N, Usuda H, et al: Gastric adenosquamous carcinoma producing granulocyte-colony stimulating factor: A case of a rare malignancy. Surg Case Rep 3: 67, 2017.

5. Matsuda T and Saika K: The 5-year relative survival rate of stomach cancer in the USA, Europe and Japan. Jpn J Clin Oncol 43: 1157-1158, 2013

6. Lewis SA, Lee MG and Cowan NJ: Five mouse tubulin isotypes and their regulated expression during development. J Cell Biol 101: 852-861, 1985

7. Yang YL, Luo XP and Xian L: The prognostic role of the class III $\beta$-tubulin in non-small cell lung cancer (NSCLC) patients receiving the taxane/vinorebine-based chemotherapy: A meta-analysis. PLoS One 9: e93997, 2014.

8. Hinsch A, Chaker A, Burdelski C, Koop C, Tsourlakis MC, Steurer S, Rink M, Eichenauer TS, Wilczak W, Wittmer C, et al: $\beta$ III-tubulin overexpression is linked to aggressive tumor features and genetic instability in urinary bladder cancer. Hum Pathol 61: 210-220, 2017

9. Lebok P, Öztürk M, Heilenkotter U, Jaenicke F, Müller V, Paluchowski P, Geist S, Wilke C, Burandt E, Lebeau A, et al: High levels of class III $\beta$-tubulin expression are associated with aggressive tumor features in breast cancer. Oncol Lett 11: 1987-1994, 2016

10. Kavallaris M, Kuo DY, Burkhart CA, Regl DL, Norris MD, Haber M and Horwitz SB: Taxol-resistant epithelial ovarian tumors are associated with altered expression of specific beta-tubulin isotypes. J Clin Invest 100: 1282-1293, 1997.
11. Ranganathan S,Benetatos CA,ColarussoPJ,DexterDW andHudes GR: Altered beta-tubulin isotype expression in paclitaxel-resistant human prostate carcinoma cells. Br J Cancer 77: 562-566, 1998.

12. Hwang JE, Hong JY, Kim K, Kim SH, Choi WY, Kim MJ, Jung SH, Shim HJ, Bae WK, Hwang EC, et al: Class III $\beta$-tubulin is a predictive marker for taxane-based chemotherapy in recurrent and metastatic gastric cancer. BMC Cancer 13: 431, 2013.

13. Cao Y, Zhang G, Wang P, Zhou J, Gan W, Song Y, Huang L, Zhang Y, Luo G, Gong J and Zhang L: Clinical significance of UGT1A1 polymorphism and expression of ERCC1, BRCA1, TYMS, RRM1, TUBB3, STMN1 and TOP2A in gastric cancer. BMC Gastroenterol 17: 2, 2017.

14. Yu Y, Ding S, Liang Y, Zheng Y, Li W, Yang L, Zheng X and Jiang J: Expression of ERCC1, TYMS, TUBB3, RRM1 and TOP2A in patients with esophageal squamous cell carcinoma: A hierarchical clustering analysis. Exp Ther Med 7: 1578-1582, 2014.

15. Burkhart CA, Kavallaris M and Band Horwitz S: The role of beta-tubulin isotypes in resistance to antimitotic drugs. Biochim Biophys Acta 1471: O1-O9, 2001

16. Brierley JD, Gospodarowicz MK and Wittekind C (eds): UICC TNM Classification of Malignant Tumours. 8th edition. Wiley Blackwell, New York, NY, 2017.

17. Kononen J, Bubendorf L, Kallioniemi A, Bärlund M, Schraml P, Leighton S, Torhorst J, Mihatsch MJ, Sauter G and Kallioniemi OP: Tissue microarrays for high-throughput molecular profiling of tumor specimens. Nat Med 4: 844-847, 1998.

18. Mirlacher M and Simon R: Recipient block TMA technique. Methods Mol Biol 664: 37-44, 2010

19. Urano N, Fujiwara Y, Doki Y, Kim SJ, Miyoshi Y, Noguchi S, Miyata H, Takiguchi S, Yasuda T, Yano M and Monden M: Clinical significance of class III beta-tubulin expression and its predictive value for resistance to docetaxel-based chemotherapy in gastric cancer. Int J Oncol 28: 375-381, 2006.

20. Nair KS, Naidoo R and Chetty R: Microsatellite analysis of the APC gene and immunoexpression of E-cadherin, catenin and tubulin in esophageal squamous cell carcinoma. Hum Pathol 37: 125-134, 2006.

21. Schlomm T, Iwers L, Kirstein P, Jessen B, Köllermann J, Minner S, Passow-Drolet A, Mirlacher M, Milde-Langosch K, Graefen M, et al: Clinical significance of p53 alterations in surgically treated prostate cancers. Mod Pathol 21: 1371-1378, 2008.

22. Panda D, Miller HP, Banerjee A, Ludueña RF and Wilson L: Microtubule dynamics in vitro are regulated by the tubulin isotype composition. Proc Natl Acad Sci USA 91: 11358-11362, 1994.

23. Falconer MM, Echeverri CJ and Brown DL: Differential sorting of beta tubulin isotypes into colchicine-stable microtubules during neuronal and muscle differentiation of embryonal carcinoma cells. Cell Motil Cytoskeleton 21: 313-325, 1992.

24. Tsourlakis MC, Weigand P, Grupp K, Kluth M, Steurer S, Schlomm T, Graefen M, Huland H, Salomon G, Steuber T, et al: $\beta$ III-tubulin overexpression is an independent predictor of prostate cancer progression tightly linked to ERG fusion status and PTEN deletion. Am J Pathol 184: 609-617, 2014.

25. Horak CE, Pusztai L, Xing G, Trifan OC, Saura C, Tseng LM, Chan S, Welcher R and Liu D: Biomarker analysis of neoadjuvant doxorubicin/cyclophosphamide followed by ixabepilone or Paclitaxel in early-stage breast cancer. Clin Cancer Res 19: 1587-1595, 2013.

26. Levallet G, Bergot E, Antoine M, Creveuil C, Santos AO, Beau-Faller M, de Fraipont F, Brambilla E, Levallet J, Morin F, et al: High TUBB3 expression, an independent prognostic marker in patients with early non-small cell lung cancer treated by preoperative chemotherapy, is regulated by K-Ras signaling pathway. Mol Cancer Ther 11: 1203-1213, 2012.

27. Zhang HL, Ruan L, Zheng LM, Whyte D, Tzeng CM and Zhou XW: Association between class III $\beta$-tubulin expression and response to paclitaxel/vinorebine-based chemotherapy for non-small cell lung cancer: a meta-analysis. Lung Cancer 77: 9-15, 2012.

28. Katsetos CD, Herman MM and Mörk SJ: Class III beta-tubulin in human development and cancer. Cell Motil Cytoskeleton 55: 77-96, 2003.

29. Gao S, Zhao X, Lin B, Hu Z, Yan L and Gao J: Clinical implications of REST and TUBB3 in ovarian cancer and its relationship to paclitaxel resistance. Tumour Biol 33: 1759-1765, 2012.

30. Carrara L, Guzzo F, Roque DM, Bellone S, Emiliano C, Sartori E, Pecorelli S, Schwartz PE, Rutherford TJ and Santin AD: Differential in vitro sensitivity to patupilone versus paclitaxel in uterine and ovarian carcinosarcoma cell lines is linked to tubulin-beta-III expression. Gynecol Oncol 125: 231-236, 2012. 